\title{
VERDADES SOBRE LOS 200 DÍAS
}

Sonia Roblero Rodríguez

El debate sobre la duración del curso lectivo en las escuelas y colegios públicos, se ha empantanado. Ahora resulta que la gran cuestión a decidir es si el curso dura 200 ó 174 días. ¡Cómo si esos fueran números mágicos! En ambos bandos, la leguleyada, la reducción de los asuntos a su gaceta jurídica, alcanza en este caso la máxima expresión, y con ello, desemboca en el absurdo.

En realidad el problema es otro. Consiste en que la ampliación del curso obedeció a un criterio puramente contable, como si el gran objetivo fuera que la suma final arrojara un resultado de 200 días... exactos. Pero este es un planteo totalmente simplista y que solo resulta intangible y justificado si se lo coloca en el contexto leguleyo antes señalado.

Tal planteo llevó a un manejo desacertado de la cuestión. De las múltiples dificultades que originó, destaco la que me parece más importante. Se hizo caso omiso de 
que las diferentes etapas del proceso educativo tienen sus duraciones específicas; las cuales no pueden alterarse arbitrariamente sin producir consecuencias desastrosas.

Por ejemplo, en virtud de este culto reverencial a los 200 días ocurren situaciones como las siguientes:

- La primera convocatoria para aplazados se realiza una semana después de haber concluido las lecciones. Se ha convertido así en un mero gesto, en un simple saludo a la bandera, en una oportunidad ficticia. Porque, ¿puede alguien sensato creer que un estudiante será capaz de recapitular en una semana los contenidos anuales de una, dos o hasta tres asignaturas? El resultado es que ahora un contingente muy numeroso de estudiantes pasa a segunda convocatoria.

- Pero estos estudiantes que deben presentar segunda convocatoria (precisamente los casos más problemáticos en materia de aprendizaje), se incorporan a sus grupos dos semanas más tarde que el resto de sus compañeros. ¿Qué hace el profesor mientras tanto? ¿Espera a los aplazados? ¿Se olvida de ellos? ¿O hace después un reprise en atención de los recién llegados?

¿No es cierto que cualquiera de estas opciones tiene graves inconvenientes?

- La cantidad total de alumnos de las secciones y el mismo número de secciones que tendrá cada nivel, solo se establecen en forma definitiva hasta después de la incorporación de los aplazados; de los cuales, según su desempeño en el examen de convocatoria, unos regresan al nivel anterior y otros ascienden al nivel siguiente, en proporciones que no se pueden prever. Debido a ello, el tamaño de los grupos va a resultar al final fortuito y, además, por completo ajeno 
a las estipulaciones vigentes que definen el número máximo de estudiantes por sección.

Por otra parte, no son raros los casos en que a los profesores se les desarticulan, a partir del ingreso de los aplazados, los horarios y programas de trabajo fijados en un inicio, quedándoles una verdadera ensalada de niveles, así como inmensos y frecuentes "cajones" entre lección y lección.

- Los exámenes de final de cada año deben ser revisados a marchas forzadas; pues el tiempo disponible para la entrega de promedios a la administración de los colegios se restringe enormemente, debido a la prematura con que se realiza la primera convocatoria de aplazados. La situación es tal que no cabe aplicar las propias regulaciones establecidas por el Ministerio de Educación: los ocho días hábiles que el Reglamento de Evaluación da a los educadores para devolver los exámenes ya calificados, resulta en esta ocasión un plazo excesivo; si el docente se atuviera a él, con seguridad las notas no estarían listas para definir para tiempo quién aprueba o reprueba su materia. Y debe tenerse en cuenta que atienden a 300 o más alumnos, lo cual vuelve prácticamente imposible entregar promedios en menos de una semana natural.

Creo que la duración del curso lectivo debe ser la máxima posible, pero el precio de esa ampliación no debe festinar aspectos como lo aquí examinados, esenciales para la buena marcha el proceso educativo. 